\title{
Polymorphic microsatellite loci isolated from Cervus unicolor (Cervidae) show inbreeding in a domesticated population of Taiwan Sambar deer
}

\author{
D.Y. Lin ${ }^{2,3 *}$, T.Y. Chiang ${ }^{2 *}$, C.C. Huang ${ }^{4}$, H.D. Lin ${ }^{2}$, S.J. Tzeng ${ }^{5}$, \\ S.R. Kang ${ }^{6}$, H.M. Sung ${ }^{2}$ and M.C. Wu ${ }^{3}$ \\ ${ }^{1}$ Taiwan Livestock Research Institute, Council of Agriculture, Xinhua, \\ Tainan, Taiwan \\ ${ }^{2}$ Department of Life Sciences, Cheng Kung University, Tainan, Taiwan \\ ${ }^{3}$ Division of Breeding and Genetics, COA-LRI, Muchang, Xinhua, \\ Tainan, Taiwan \\ ${ }^{4}$ Kinmen National Park, Jinning Shiang, Kinmen, Taiwan \\ ${ }^{5}$ Department of Medical Laboratory Science and Biotechnology, \\ Chung Hwa University of Medical Technology, Rende, Tainan, Taiwan \\ ${ }^{6}$ Kaohsiung Animal Propagation Station, COA-LRI, Pingtung, Taiwan \\ *These authors contributed equally to this study. \\ Corresponding author: D.Y. Lin \\ E-mail: lin0429@mail.tlri.gov.tw
}

Genet. Mol. Res. 13 (2): 3967-3971 (2014)

Received February 4, 2013

Accepted August 27, 2013

Published May 23, 2014

DOI http://dx.doi.org/10.4238/2014.May.23.7

\begin{abstract}
Primers for eight microsatellites were developed; they successfully amplified DNA from 20 domesticated Formosan Sambar deer (Cervus unicolor swinhoei). All loci were polymorphic, with 10-19 alleles per locus. The average observed heterozygosity across loci and samples was 0.310 , ranging from 0 to 0.750 at each locus. All loci but one, CU18, deviated from Hardy-Weinberg equilibrium due to excessive homozygosity in these domesticated broodstocks,
\end{abstract}


reflecting inbreeding. These microsatellite loci will be useful, not only for assessment of population structure and genetic variability, but also for conservation of wild deer populations in Taiwan.

Key words: Cervus unicolor; Conservation; Microsatellite; PCR-based isolation of microsatellite arrays; RAPD-PCR enrichment

\section{INTRODUCTION}

The sambar deer (Cervus unicolor swinhoei), the largest Oriental deer, is widespread in South and East Asia. Human introductions on other continents, including countries such as New Zealand, Australia, United States, and South Africa, make the distribution range wider. In total, seven subspecies have been recognized. They grow in various habitats ranging from tropical rainforests to subtropical mixed forests (David, 2011). Ever since the 1980s, overexploitation of natural forests and hunting as well as abiotic effects causing habitat fragmentation and niche deterioration has inevitably led to consequent shrinkage of sambar deer populations. Considering the small population census size of various ethnic groups, despite its worldwide distribution, the sambar deer has been recognized as vulnerable to high risks of being extinct at the local or regional scale (Timmins et al., 2008).

The Formosan Sambar, C. unicolor swinhoei, is one of the sambar deer subspecies exclusively found in Taiwan. It is also the largest native herbivore on the island (Chan et al., 2009), and inhabits mature forests at altitudes above $1500 \mathrm{~m}$ of the Huatung Mountains and the Central Mountain Range in small sizes (Wang et al., 2003; Wu et al., 2004; Lee et al., 2006; Wang et al., 2008). The Formosan Sambar has been raised as a farm animal for more than one hundred years. With the increasing demands for the marketing of meat and traditional Chinese medicine, the Formosan Sambar is mostly found on deer farms. For this purpose, the Formosan Sambar has been established as domestic livestock derived from wild populations, thus representing genetic resources that provide insights into the evolutionary changes over the course of domestication.

Microsatellite loci are short sequences of nucleotides (typically 1 to $5 \mathrm{bp}$ ) which are tandemly repeated and exist along the eukaryotic genome. The advantages of high genomic abundance, high levels of polymorphism, high reproducibility, and co-dominance inheritance make microsatellites ideal molecular markers for genotyping and population genetics. In addition, areas such as conservation biology, linkage analysis of QTL mapping and forensics also benefit from the development of microsatellites. However, the de novo development of microsatellite markers is time-consuming and economically costly (Zane et al., 2002). Previously, most of the microsatellite markers for deer have been available as either bovine- or ovine-specific primer pairs (Okada and Tamate, 2000; Vial et al., 2003; Zachosb et al., 2003; Zsolnai et al., 2009; Pérez-González et al., 2010). Therefore, in this study we isolated eight novel polymorphic microsatellite markers from C. unicolor swinhoei using PCR-based isolation of microsatellite arrays (PIMA; Lunt et al., 1999).

\section{MATERIAL AND METHODS}

Samples were collected from 20 Formosan Sambar deer at the Kaohsiung captive breeding farm in Kaohsiung city, Taiwan. Total genomic DNA was extracted from blood samples 
with PUREGENE DNA isolation kits (Gentra System, MN, USA). A PCR library was obtained by the PCR-based isolation of microsatellite arrays (PIMA) method, which is based on random amplified polymorphic DNA-polymerase chain reaction (RAPD-PCR) enrichment, via cloning of amplified DNA fragments into a pGEM T-Easy vector system (Promega, Madison, WI, USA) and screening of the library for microsatellites by PCR with both vector primers and a target microsatellite-specific primer (GT and GA repeats) (Lunt et al., 1999). It takes advantage of the fact that the RAPD fragments contain microsatellite repeats more frequently than do random genomic clones (Cifarelli et al., 1995). PCR was performed in a $15-\mu \mathrm{L}$ final volume containing $0.2 \mathrm{mM}$ each dNTP, $2 \mathrm{mM} \mathrm{MgCl}, 0.5 \mathrm{U}$ Taq polymerase (Promega), and 5 pmol RAPD primer. Several RAPD primers were adopted to amplify fragments coming from the target species genome in separate reactions. PCR amplifications were conducted in a thermal cycler (Bio-Rad). The PCR program was as follows: initial denaturation at $94^{\circ} \mathrm{C}$ for $3 \mathrm{~min} ; 40$ cycles of $94^{\circ} \mathrm{C}$ denaturation for $50 \mathrm{~s}, 37^{\circ} \mathrm{C}$ annealing for $1 \mathrm{~min}$ and $72^{\circ} \mathrm{C}$ extension for $1 \mathrm{~min}$; and $72^{\circ} \mathrm{C}$ for $10 \mathrm{~min}$.

RAPD-PCR products were size-selected to preferentially obtain small fragments (500-1200 bp). Approximately 100 ng PCR product were ligated into a pGEM T-Easy vector (Promega) according to manufacturer instructions, and the ligation mixture was transformed into Escherichia coli DH5a competent cells. To determine clones containing microsatellite fragments from a constructed microsatellite library, both primer sets that are specific to the vector region and microsatellite repeat sequences (e.g., GT and GA repeats), respectively, were used in a PCR reaction. The appearance of PCR amplicon, flanked by vector and microsatellite repeats, represents an indicator to discriminate clones with or without microsatellites.

Plasmid DNAs from positive clone were purified with the High-Speed Plasmid Mini kit (Geneaid). Both strands of the DNA insert were sequenced. Sequencing of positive insert PCRs was conducted with an ABI PRISM 3730 sequencer using the BigDye Terminator kit (Applied Biosystems, Foster City, CA, USA) with vector primers. For the selected loci, PRIMERS3 software (Rozen and Skaletsky, 2000) was used to design oligonucleotide primers for flanking regions.

Preliminary assessment of polymorphism was performed in 20 Formosan Sambar individuals collected from dear farms in Taiwan, and PCR conditions were optimized for each pair of primers. Reactions were performed in a total volume of $20 \mu \mathrm{L}$ containing $10 \mathrm{ng}$ genomic DNA, $0.2 \mathrm{mM}$ dNTP, $2 \mathrm{mM} \mathrm{MgCl}$, and $0.12 \mu \mathrm{M}$ each primer. PCR reactions were as follows: $94^{\circ} \mathrm{C}$ for 4 min followed by 40 cycles at $94^{\circ} \mathrm{C}$ for $30 \mathrm{~s}, 30-50 \mathrm{~s}$ at primer-specific annealing temperature (Table 1) and $72^{\circ} \mathrm{C}$ for $45 \mathrm{~s}$, and a final extension step at $72^{\circ} \mathrm{C}$ for 10 min. Individuals were genotyped on $6 \%$ denaturing polyacrylamide gels stained with ethidium bromide and sized by comparison to a 10-bp DNA ladder standard (Invitrogen).

Conversion of the genotype data files for different analyses of the microsatellites was carried out using CREATE (Coombs et al., 2008) to minimize errors. Analyses of polymorphism including determination of allele diversity (allele number, $N_{\mathrm{A}}$ ) and observed $\left(H_{\mathrm{O}}\right)$ and expected $\left(H_{\mathrm{E}}\right)$ heterozygosities were performed using GENEPOP (Raymond and Rousset, 1995). The exact test fit to Hardy-Weinberg equilibrium (HWE) and linkage disequilibrium for all pairs of loci within the population was performed using ARLEQUIN 3.5 (Excoffier and Lischer, 2010). Tests for significance for all multiple loci were corrected by sequential Bonferroni procedures (Rice, 1989). The MICROCHECKER software was employed to infer the most probable technical cause of HWE departures, including null alleles, allelic dropout due to short allele dominance, and errors made during the scoring of alleles with 'stutter' in our data (Van Oosterhout et al., 2004). 
Table 1. Forward $(\mathrm{F})$ and reverse $(\mathrm{R})$ primer sequences, repeat motif, allele size range, annealing temperature $\left(\mathrm{Tm}^{\circ} \mathrm{C}\right)$, number of observed alleles $\left(N_{\mathrm{A}}\right)$, observed $(H \mathrm{o})$ and expected heterozygosity $\left(H_{\mathrm{E}}\right)$, and Chi-square tests for Hardy-Weinberg equilibrium (HWE) after Bonferroni correction (adjusted P value $=0.00625$ ) for eight microsatellite loci in Cervus unicolor.

\begin{tabular}{|c|c|c|c|c|c|c|c|c|c|}
\hline Locus & $\begin{array}{l}\text { Accession } \\
\text { No. }\end{array}$ & Primer sequence (5' to $\left.3^{\prime}\right)$ & $\begin{array}{c}\text { Repeat } \\
\text { motif }\end{array}$ & $\begin{array}{l}\text { Size range } \\
\quad(b p)\end{array}$ & $\operatorname{Tm}\left({ }^{\circ} \mathrm{C}\right)$ & $N_{\mathrm{A}}$ & $H_{\mathrm{o}}$ & $H_{E}$ & $\begin{array}{l}\text { HWE } \\
\text { P value }\end{array}$ \\
\hline$\overline{\mathrm{CU} 02}$ & & $\begin{array}{l}\text { F: GGGAGTCCTTCCTGTTCCTT } \\
\text { R: CCAAGATCCCCCTTCTTGTT }\end{array}$ & $(\mathrm{CT})_{9}$ & $235-252$ & 55 & 13 & 0.000 & 0.933 & $0.000^{*}$ \\
\hline CU04 & & $\begin{array}{l}\text { F: CAGCACGAAGGCCTAACCTA } \\
\text { R: CCCTTCCAGCCCATCTAAA }\end{array}$ & $(\mathrm{AG})_{12}$ & $279-303$ & 55 & 14 & 0.266 & 0.949 & $0.000 *$ \\
\hline CU05 & & $\begin{array}{l}\text { F: AACAGCCTCACACACTCCAA } \\
\text { R: CCTTTCTCTCTGTGGCCAGT }\end{array}$ & $(\mathrm{AG})_{9}$ & $218-261$ & 55 & 19 & 0.750 & 0.948 & $0.000 *$ \\
\hline CU06 & & $\begin{array}{l}\text { F: CATTGAGCTCCAATCCAGTG } \\
\text { R: GTGAAACAAACCCAAAATTCTAA }\end{array}$ & $(\mathrm{CT})_{14}$ & $291-325$ & 55 & 11 & 0.157 & 0.900 & $0.000^{*}$ \\
\hline CU09 & & $\begin{array}{l}\text { F: AGACATGCACAAGGCTCCTC } \\
\text { R: GACTCCAAGCACTGGGATACA }\end{array}$ & $(\mathrm{AG})_{10}$ & $219-234$ & 55 & 10 & 0.000 & 0.892 & $0.000^{*}$ \\
\hline CU10 & & $\begin{array}{l}\text { F: CCCACTCGCACTCTCTCTCT } \\
\text { R: ACTCAAGGGCCAGGGACTAT }\end{array}$ & $(\mathrm{AG})_{18}$ & $229-246$ & 55 & 14 & 0.473 & 0.876 & $0.000^{*}$ \\
\hline CU17 & & $\begin{array}{l}\text { F: CAGCATAATTTAGGTGATGAGGTTT } \\
\text { R: CACTATTTACCCAGAATCAAAGCA }\end{array}$ & $(\mathrm{AG})_{8}$ & $304-340$ & 50 & 10 & 0.100 & 0.873 & $0.000^{*}$ \\
\hline CU18 & & $\begin{array}{l}\text { F: GTGGTTGGAAGGTGTGTGTG } \\
\text { R: TTGCAGGCTACAGTTCATGG }\end{array}$ & $(\mathrm{GT})_{14}$ & $233-264$ & 55 & 17 & 0.736 & 0.914 & 0.009 \\
\hline
\end{tabular}

*Significant deviation from HWE $(\mathrm{P}<0.00625)$.

\section{RESULTS AND DISCUSSION}

The number of alleles per locus ranged from 10 to 19 (Table 1). $H_{\mathrm{O}}$ varied from 0.000 to 0.750 (average $H_{\mathrm{O}}=0.310$ ), with the highest at CU05 and lowest at CU02. $H_{\mathrm{E}}$ was 0.910 across all loci. The highest $H_{\mathrm{E}}$ was observed at locus CU04 $\left(H_{\mathrm{E}}=0.949\right)$ and the lowest at CU17 $\left(H_{\mathrm{E}}=\right.$ 0.873). After applying sequential Bonferroni corrections to compensate for multiple statistical tests, no evidence of genotypic linkage disequilibrium was detected among the loci $(\mathrm{P}>0.00625)$. All loci but one (CU18) significantly deviated from Hardy-Weinberg equilibrium following sequential Bonferroni adjustment $(\mathrm{P}<0.00625)$, suggesting a significant heterozygote deficit for these loci. These deviations may have resulted from the sampling strategy in which all individuals were collected from closed broodstock lineages. Other reasons included intensive inbreeding as well as artificially selective mating in a small number of individuals, leading to dramatic losses of genetic polymorphisms (heterozygosity). Microsatellite makers obtained from reared individuals would help monitor population dynamics and determine dispersal patterns and genetic diversity within and between wild populations of the Formosan sambar deer, given the short history of domestication. These microsatellite loci will be used to explore population structuring and extent of gene flow between wild $C$. unicolor populations, providing better understanding of the ecological fluctuations and serving as a foundation for a conservation management framework in the future.

\section{ACKNOWLEDGMENTS}

We thank Kun-Feng Lin and Chih-Hua Wang for helping in sample collection.

\section{REFERENCES}

Chan JP, Tsai HY, Chen CF, Tung KC, et al. (2009). The reproductive performance of female Formosan sambar deer 
(Cervus unicolor swinhoei) in semi-domesticated herds. Theriogenology 71: 1156-1161.

Cifarelli RA, Gallitelli M and Cellini F (1995). Random amplified hybridization microsatellites (RAHM): isolation of a new class of microsatellite-containing DNA clones. Nucleic Acids Res. 23: 3802-3803.

Coombs JA, Letcher BH and Nislow KH (2008). create: a software to create input files from diploid genotypic data for 52 genetic software programs. Mol. Ecol. Resour. 8: 578-580.

David ML (2011). Rusa unicolor (Artiodactyla: Cervidae). Mammalian Species 43: 1-30.

Excoffier L and Lischer HEL (2010). Arlequin suite ver 3.5: A new series of programs to perform population genetics analyses under Linux and Windows. Mol. Ecol. Res. 10: 564-567.

Lee LL, Lin CY and Tsai CG (2006). Food Habitats and Population Ecology of Formosan Sambar deer (Rusa unicolor swinhoei) at Yu-Li Wild life Refuge. Council of Agriculture, Taipei, Taiwan, 64.

Lunt DH, Hutchinson WF and Carvalho GR (1999). An efficient method for PCR-based isolation of microsatellite arrays (PIMA). Mol. Ecol. 8: 891-893.

Okada A and Tamate HB (2000). Pedigree Analysis of the Sika Deer (Cervus nippon) using Microsatellite Markers. Zoolog. Sci. 17: 335-340.

Pérez-González J, Carranza J, Torres-Porras J and Fernandez-Garcia JL (2010). Low heterozygosity at microsatellite markers in Iberian red deer with small antlers. J. Hered. 101: 553-561.

Raymond $\mathrm{M}$ and Rousset $\mathrm{F}$ (1995). GENEPOP (version 3.2): population genetics software for exact tests and ecumenicism. J. Hered. 86: 248-249.

Rice WR (1989). Analyzing tables of statistical tests. Evolution 43: 223-225.

Rozen S and Skaletsky HJ (2000). Primer3 on the WWW for General Users and for Biologist Programmers. In: Bioinformatics methods and protocols: methods in molecular biology (Krawetz S and Misener S, eds.). Humana Press, NJ. 365-386.

Timmins RJ, Steinmetz R, Baral SH and Kumar SN (2008). Rusa unicolor. In: IUCN 2009. IUCN Red List of Threatened Species.

Van Oosterhout C, Hutchinson WF, Willis DPM and Shipley P (2004). MICRO-CHECKER: software for identifying and correcting genotyping errors in microsatellite data. Mol. Ecol. Notes 4: 535-538.

Vial L, Maudet C and Luikart G (2003). Thirty-four polymorphic microsatellites for European roe deer. Mol. Ecol. Notes 3: 523-527.

Wang Y, Wang CC, Kuo CY and Wu HJ (2003). Status of Large Mammals in Taiwan. Council of Agriculture, Taipei, Taiwan, 28.

Wang Y, Yen SC, Liao CH and Yeh CW (2008). Alpine Ecosystem of Taroko National Park -The Study on Formosan Sambar deer's (Rusa unicolor swinhoei) habitat use. Headquarter of Taroko National Park, Ministry of Interior, 52.

Wu HY, Wu SH and Wu YH (2004). Fuana Survey in Alpine area of Taroko National Park. Headquarter of Taroko National Park, Ministry of Interior, 66.

Zachosb F, Hartla GB, Apolloniob M and Reutershana T (2003). On the phylogeographic origin of the Corsican red deer (Cervus elaphus corsicanus): evidence from microsatellites and mitochondrial DNA. Mamm. Biol. 68: 284-298.

Zane L, Bargelloni L and Patarnello T (2002). Strategies for microsatellite isolation: a review. Mol. Ecol. 11: 1-16.

Zsolnai A, Lehoczky I, Gyurmán A and Nagy J (2009). Development of eight-plex microsatellite PCR for parentage control in deer. Archiv Tierzucht 52: 143-149. 